\title{
Formas e lugares fantasmas da memória colonial e pós-colonial
}

Ana Mafalda Leite

Universidade de Lisboa

RESUMO: O ARTIGO DISCUTE, SEGUINDO SEMPRE NAS ENTRELINHAS AS REFLEXÕES DE HOMI BHABHA EM O LOCAL DA CULTURA, OS DIVERSOS MODOS DE DESVELAMENTO DA MEMÓRIA (COLONIAL E PÓS-COLONIAL) NAS NARRATIVAS DE MANUEL RUI (O MANEQUIM E O PIANO) E DE JOÃO PAULO BORGES COELHO (SETENTRIÃO), MOSTRANDO COMO OS ROTEIROS E O DESLOCAMENTO POR NOVOS LUGARES E ESPAÇOS IMPLICAM UM RE-MAPEAMENTO DA NAÇÃO E SIMULTANEAMENTE UM REPENSAR DE VÁRIOS MOMENTOS DA HISTÓRIA. DISCUTE-SE AINDA DE QUE MODO A ESCRITA NARRATIVA DOS AUTORES COMPROMETE OS VALORES CANÓNICOS DO ROMANCE OU DO CONTO, DANDO ABERTURA A CRUZAMENTOS DE MATRIZES ÉPICAS E ROMANESCAS E AINDA DO MEMORIALISMO.

ABSTRACT: THIS ARTICLE DISCUSSES DIFFERENT MODES OF UNVEILING THE (COLONIAL AND POST-COLONIAL) MEMORY IN THE NARRATIVES OF MANUEL RUI (O MANEQUIM E O PIANO) AND JOÃO PAULO BORGES COELHO (SETENTRIÃO), IN THE LIGHT OF HOMI BHABHA'S REFLECTIONS IN NATION AND NARRATION, SHOWING HOW THE ITINERARIES AND DISPLACEMENT THROUGH NEW PLACES AND SPACES IMPLY A RE-MAPPING OF THE NATION AND SIMULTANEOUSLY A RE-THINKING OF SEVERAL MOMENTS IN HISTORY. FUTHERMORE, IT IS DISCUSSED HOW THE NARRATIVE WRITING OF THE STUDIED AUTHORS QUESTIONS THE CANONICAL VALUES OF THE NOVEL OR SHORT STORY, OPENING ROOM TO INTERSECTIONS OF EPIC AND ROMANCE SOURCES, AND EVEN MEMORIALISM.

PALAVRAS-CHAVE: MEMÓRIA, DESLOCAMENTO, GÉNERO LITERÁRIO, NAÇÃO. KEYWORDS: MEMORY, DISPLACEMENT, LITERARY GENRE, NATION. 
manequim e o piano (2005), romance do escritor angolano Manuel Rui, e o volume de contos Setentrião (2005), do moçambicano João Paulo Borges Coelho, reinvestem a arquitectura local de suas narrativas de uma memória em processo de se reconstituir, que articula e costura vários tempos, entre retratosestórias da época colonial e uma memória mais recente, da guerra civil, no período pós-independência.

$\mathrm{O}$ intuito deste texto é mostrar como essas obras descrevem imagens/ temas de uma memória, refeita pela releitura de diferentes espaços regionais dos seus países, em que se desvela o conhecimento da época colonial e também pós-colonial. Essas regiões culturais, mais periféricas, como o Huambo e o norte de Moçambique, são desocultadas, assim como o acesso a uma recomposição fragmentária da memória colonial, alargando e diversificando a narrativa da nação, permitindo repensar a heterogénea pluralidade daquela.

Por outro lado, as formas narrativas dos textos manifestam uma combinatória composicional que articula matrizes da novelística, da narrativa memorialística e do romance a outras de matriz oral, reinvestindo as concepções de género literário, atribuídas aos textos, de ambiguidade e de uma certa irresolução formal.

Assim, nos textos de Manuel Rui e de João Paulo Borges Coelho, encontramos esse caminho de revisão fragmentada da memória do período colonial, recolocando-se a agência desse tempo/espaço no sujeito pós-colonial, que pode activar e repensar uma memória, que na época colonial lhe era negada. Recupera-se do passado uma pedagogia, que algumas imagens da memória devem ilustrar, realizando-se em simultâneo o movimento de descentralização de uma canonicidade literária, tendencialmente urbana, e por vezes mais ou menos essencialista, das respectivas literaturas, para uma abertura à pluralidade cultural e à revisão da história.

Esta estratégia discursiva, que as obras de João Paulo Borges Coelho e de Manuel Rui realizam, questiona também a relação de subalternidade existente entre periferias e centros nos respectivos países, assim como a lógica norte/ sul, deslocada por sua vez para o espaço das nações do sul, que congrega nas capitais os núcleos do poder político, económico e cultural.

Os fragmentos do passado colonial e do presente pós-colonial, reincorporados nas narrativas angolana e moçambicana, são sujeitos a uma reescrita, e simultaneamente à inscrição no corpo da narrativa nacional, enquanto ves- 
tígios de sujeitos diferenciais e de vozes heterogéneas, de processos compositivos novos, alargando-se aquela em processos que cruzam diacronia com sincronia em movimentos de inesperada escripturação.

Os fragmentos, retalhos e restos da vida cotidiana devem ser repetidamente transformados nos signos de uma cultura nacional coerente, enquanto o próprio acto de performance narrativa interpela um círculo crescente de sujeitos nacionais. $\mathrm{Na}$ produção da nação como narração ocorre uma cisão entre a temporalidade continuísta, cumulativa do pedagógico e a estratégia repetitiva, recorrente, do performativo. É através deste processo de cisão que a ambivalência conceitual da sociedade moderna se torna o lugar de escrever a nação. (BHABHA, 1998:207)

Começo por questionar algumas das relações que se estabelecem entre Memória e História. As duas são representações do passado e uma pressupõe a outra, mas enquanto a primeira é fundadora, a segunda legitima. Enquanto a história procura distanciar-se do passado para o representar, a memória procura fundir-se com ele. A imediatez e a fragmentação da memória distinguem-se também do carácter mediático da história, do seu envolvimento nas continuidades temporais, evolutivas e relacionais.

Pierre Nora chama a atenção para a relação sacral da memória, para o seu lado afectivo e mágico, enraizado no concreto, na imagem, no gesto, no objecto, nos pormenores e fragmentos, das lembranças vagas, ou mais precisas, globais ou parcelares, simbólicas, muitas vezes num jogo de descontinuidades no tempo: "Ouverte à la dialectique du souvenir et de l'amnésie, inconsciente de ses déformations successives, vulnérable à toutes les utilisations et manipulations, susceptible de longues latences et de soudaines revitalisations" (1984:XV-XLII).

Sabemos que a história utiliza certos traços da memória para recompor o passado, a partir de fragmentos escolhidos; o passado torna-se legível, a partir do momento em que o historiador efectua uma selecção, em torno de um, ou de vários centros de interesse. Os documentos e arquivos são sujeitos a uma interrogação orientada, bem como à procura de uma possível, e mais ou menos positivista, "objectividade" da representação.

Apesar disso a história é também selectiva e põe de lado certos acontecimentos, usa de uma certa arbitrariedade nas suas aproximações, categorias e sequências temporais, como no caso da história das mentalidades, da antropologia histórica ou da micro-história. 
Pode, no entanto, dizer-se que a memória dá conta de uma outra representação dos acontecimentos, mais difícil de encontrar na versão restituída pelo trabalho do historiador? Pierre Vidal-Naquet (1991:392) insiste nessa aptidão da memória em fazer surgir pormenores, que interessam normalmente o romancista, numa tentativa de reavaliação da história. A dimensão subjectiva, inventiva e ficcional do escritor, ao criar mundos imaginários, distingue-se da tarefa do historiador, que tenta repor e perseguir uma representação da "verdade(?)" dos factos.

$\mathrm{O}$ manequim da memória

... deve haver aí um mistério qualquer entre esse manequim e... e o quê Alfredo? Entre o manequim e tudo que acontece connosco desde que chegámos aqui porque nada acontece por acaso quem sabe se o manequim tem uma ligação com a nossa casa porque nós conhecemos o manequim antes de encontrarmos a casa e a chuva a trovoada os eucaliptos tu não achas que há qualquer ligação? (MP:119)

Encontramos essa apreensão afectiva, fragmentária e sacral, da memória em O manequim e o piano, ${ }^{1}$ narrativa que conta como dois coronéis - Alfredo e Vander -, após o final da guerra civil em Angola, regressam ao sul, a Huambo, a terra natal do primeiro, com o objectivo de começar uma vida nova. Logo no início do romance de Manuel Rui há uma referência directa à memória, que vai sendo actualizada, em cruzamentos dispersivos, pelo olhar que percorre o espaço da cidade, situando a origem e oferecendo o relato biográfico:

... isto contava Alfredo esticando constantemente o braço direito e apontando com o dedo indicador a refazer memória e em frente ao palácio do município (...) É esta a casa (fala de Alfredo) sim senhor e foi por um triz se o meu pai não se tivesse metido nas eleições do Humberto Delgado mais uns reviralhistas de Nova Lisboa o velho é que me contava que nessa altura eu estaria para nascer... (MP:8)

Também nos contos "O pano encantado", "Casas de ferro", "O Hotel das duas portas" e "Ibo azul", de Setentrião, cujos enredos se situam no norte e

1. Doravante, "MP".

2. Doravante, "S". 
centro de Moçambique, nomeadamente, na Ilha de Moçambique, Beira, Ilha de Santa Carolina e Ibo, se indaga uma memória, que o espaço deixa entrever:

Vinha do lado de Munaua, este estrangeiro, e ela arrepiou-se por ser esse o lado onde habita gente do passado. (...) As ruas largas fizeram-se tortuosos caminhos, as casas bichos mortos, os habitantes, um a um, foram migrando para Munaua, o bairro dos silêncios e das pedras, sem sequer olhar para trás. Memórias têm os vivos. (S:204-208)

É através da viagem, pois se trata sempre de uma tentativa de refazer roteiros, que os narradores, ou narradores-personagem, em deambulação peregrina, indagam o reconhecimento arquitectural das ruas, edifícios, dos fragmentos e restos de mapas de um tempo anterior, colonial, quase irreconhecível, em demanda ou da teia de uma biografia pessoal, ou da reconstituição parcial e fantasmática de cenas de uma época.

Agora como somos todos amigos todas as alianças são para evitar inimizades obtendo uma vitória, isto é, a casa, e o homem assobiava sozinho na recordação da infância quando imitava os sakanjueres gordos a cantar em cima das mangueiras com as borboletas de asas abertas desenho de caveira em cada asa preta amarela e branca asas grandes e o homem só queria era andar a pé em caminhos que lhe diambavam regressar num jeito de engano combinado consigo próprio de que regressava sem nunca ter saído nessa penumbra da memória onde guardava em descompreendido esquecimento a casa o quintal de crescer a família os colegas de escola os amigos de nadar nos rios proibidos. (MP:195-6)

A visitação destes lugares, cidades e ilhas, periféricos, relativamente aos grandes centros urbanos dos países, provoca um efeito de deslocamento e de descentralização das capitais hegemónicas do poder e da representação do locus literário da nação.

Verificamos assim que o romance de Manuel Rui investe no presente da escrita a sedimentação de duas memórias temporais, uma mais recente, a da guerra civil, e outra, mais antiga, a do tempo colonial, revisitada por uma tessitura biográfica. Por seu turno, os contos de João Paulo Borges Coelho 
reapropriam-se de "lugares" para questionação de fragmentos culturais, desde religiosos a linguísticos, biográficos, nas remotas ínsulas da costa índica, ou nas cidades do interior, confrontando-os com o presente da história. Como Rita Chaves (2008:188) observa "Essa demarcação espacial torna-se um dado importante na medida em que promove o deslocamento em relação ao interior e ao Norte de Moçambique, ampliando também o que podemos conhecer como a territorialidade literária do país".

O conto "O pano encantado" metaforiza esse processo de costura de fragmentos, restos, ruínas, de tempos, que se equivalem na figuração da morte, que revive fantasmaticamente, como, por exemplo, no conto "O hotel das duas portas", em que o narrador-cadáver conta uma memória perdida na remota ilha de Santa Carolina. De modo similar à imagem do Manequim simboliza a figuração fantasma de uma presença-ausente, a criação da memória enquanto des(articulação) temporal entre a morte/vida.

Ainda ontem vi esse manequim que anda em todo lado como uma sombra (p. 94); os manequins também gigantes maneira de tchinganjis carregados de feitiço estás a ver não é? e alguns desses manequins pintados de várias cores às riscas uns como os da Lunda os quê? Mukiches. (MP:50)

E quando todos tiverem também partido, daqui a muito tempo, quando o futuro for branco como brancos e salgados vão ser os meus ossos, assistirei à queda dos telhados e à serena invasão dos capins, à erosão do bar e ao assomar fulgurante do mar na superfície encerada do piso do salão, ao ruir das paredes manchadas de sangues nas duas salas que há atrás daquelas duas portas. Quando já não fizerem sentido os fragmentos que sobrarem, inesperados e arbitrários como se a natureza tivesse enlouquecido, ali vos estarei esperando. (S:115-6)

A memória é a capacidade de atribuir as lembranças a partir de lugares, criando-se uma relação em que o espaço como que se metamorfoseia em tempo. Nesse sentido, os lugares configuram-se como imagens/vestígios de fragmentos de vida/tempo. A condição de vestígio e ruína impossibilita a concepção de uma memória intacta, mas reafirma a capacidade de transformar seus fragmentos em relatos que tornam inteligíveis as arquitecturas/ os lugares do passado.

O carácter fragmentário da memória metaforiza-se assim na ruína dos edifícios, das casas, das carcomidas paredes, na mineralização dos silêncios, que 
as lápides congregam, e na invasão com que se impõe a verdura trepadeira do esquecimento.

Cada caminho como se fosse ainda a rua que foi, no tempo em que era viva a espera dos quietos moradores deste exíguo bairro de Munaua a que desde 1886 chamam de cemitério. No tempo em que se passeavam nos seus trajes antigos por essas ruas, talvez de casaca em pleno Verão, talvez ocupados apesar da ecuménica lentidão. Em cada esquina o sussurro exalado de uma língua que se perdeu, fugindo dos sons para a escrita, do papel para o pó. (S:191)

É através do recurso aos trajectos, que encontramos em quase todos os contos de JPBC, em que a descrição dos nomes dos bairros e ruas, a procura de lugares públicos, o percurso de ruas, ruelas e atalhos, que se faz a evocação de uma memória praticamente desaparecida, em que os vestígios arquitecturais,"esqueléticos" como o corpo articulado do manequim despido, evocam imagens oximóricas, porque confrontadas, ou com a ruína dos edifícios ou com o total esvaziamento dessa referida memória no presente.

Estas imagens, quase idênticas a postais muito antigos, meio apagados, convocam estórias silenciadas, porque anónimas, articulam a temporalidade no espaço, impregnando-se este último de presenças fantasmáticas, invasoras, mas de difícil acesso à representação.

Não podia saber - salvo um ou outro morador, velhos demais para que a sua vOz fosse escutada, ninguém sabia - que este Grande Hotel era anterior ao tempo dos colonos, que nesse tempo ele estava já encerrado e silencioso, antecipando a morte deles quando esta ainda mal se anunciava. Era uma casa mais antiga, do tempo em que os colonos não eram ainda colonos mas senhores e muzungos, um tempo sem consciências nem protestos. (S:50)

A tematização da memória aparece obsessivamente em $O$ manequim e o piano. Vander tira notas e escreve nos seus caderninhos ("se perder as notas perco o livro se perder o livro perco a casa” [p. 306]). O livro-casa, que é afinal o romance, é também o lugar de permanência e ocultação de tempos fantasmas, como o da guerra civil e o da época colonial. A casa assombrada, que ninguém ousa ocupar, e que os dois militares ("todas as pessoas olhavam 
para eles como se fossem seres ressuscitados de um passado" [p. 27]), querem a todo o custo fazer sua, inscreve no presente uma memória necessária, a da reescrita do passado. Essa casa-umbigo, de temor e de terror, desabitada, e centro da narrativa de MR, é clandestinamente visitada durante a noite pelos dois protagonistas e representa, por um lado, a imaginada reconstrução do domus natal, sedimentando as várias versões da sua genealogia fantasmática. Por outro lado permite também a reconstrução das memórias, que se organizam em paralelo através da escrita do romance, casa em processo, "mise en abîme" em anotação, indagando-se o espaço temporalmente conquistado:

... depois pára corre volta a parar inventa rotas sem um objectivo e quando faz uma opção é sempre em linha recta ele concluiu que não vale a pena definir rumos com a bússola (...) havia muitos círculos aparentemente invisíveis mas concêntricos passando por fantasmas ligações pessoas sorrisos e olhares que de repente ele já conhecia e se conheciam todos dando a impressão que só agora com a paz se tinham conhecido numa amnésia de nunca se terem conhecido nas horas de guerra e assim o homem também fazia de conta que havia perdido a memória para compreender que as pessoas ali tinham-se ressuscitado numa nova forma de estarem vivos recordando o futuro na risada do medo para construir uma memória. (p. 254)

\section{Chuva \& piano - som \& voz}

A rememoração que a figura do manequim encena é antecipada no início da narrativa de Manuel Rui, pelo som da chuva, bem como pelo som de um piano e de canto, numa espécie de significância anterior à palavra, irrepresentável e inarticulável, também desenquadrada de uma temporalidade diacrónica, como que fora do tempo: "nesse quando", "no sem tempo", "e isso era passado":

Relvados desenhados por geometria dos canteiros no meio com flores de muitos aromas e colorido nos sons as asas dos pássaros peitos-celestes bicos-delacre viuvinha enchendo o cheiro nas pessoas até de longe num respirar de dia solto e nesse quando a noite dava vez no cacimbo e a gente com o frio 
se enroupava para qualquer muito comprida hora de chuva miudinha essas próprias flores no sem tempo de sentir a vida na desconspiração coma grande orquestra de verde(...) (desta matéria falava a fala de Alfredo) Vander vira que volta a tomar notas no pequeno-bloco e isso era passado o medos trovões e zigue-zagues das faíscas onde o granito também musicava... . (p. 7)

A incapacidade de situar no tempo a memória, feita de ziguezagues e de combinatórias diversas, reproduzindo um fluxo de consciência, é acompanhada no romance de Manuel Rui da quase impossibilidade de a traduzir em palavras, ou seja, a memória é também aquilo que fica "fora da frase", de certo modo como se ela fosse irrepresentável; assim a casa assombrada liga-se à música do piano, que apenas é ouvida pelos dois militares, que convoca reminiscências de infância e da época colonial, e acompanha a evolução narrativa como motivo recorrente, tal como o Manequim. A propósito desse encantamento pela música do piano, e sua linguagem intraduzível, Alfredo, na sua contínua interlocução com Vander, em que o calão e o coloquialismo se recortam, diz: "porra que falo português pra caralho mas fica-me essa raiva de não ter aprendido piano ombre" (p. 9). Por seu turno, também a Vander, que tira continuamente notas de escrita, lhe escapa uma diversa escrita, a das notas de piano.

Em vários momentos da narrativa há como que uma orquestração entre o som da natureza e o da cultura; a chuva purificadora, e desejada pelas personagens, cadencia o ritmo da rememoração, que localiza a região do Huambo, alternando, ou a par do som do piano. Reconhecimento auditivo que percute imagens e referências antigas, estes sons fora de qualquer frase, quase uma espécie de locus amoenus em estado de intradutibilidade, fazem lembrar uma passagem de O prazer do texto de Roland Barthes, em que o ensaísta reflecte sobre uma descrição de uma praça de Tânger:

Em mim isso também falava (é coisa conhecida), e essa fala dita interior parecia muito com o rumor da praça, com esse escalonamento de pequenas vozes que me vinha do exterior: eu mesmo era um lugar público, um souk; em mim passavam as palavras, os pequenos sintagmas, as pontas de fórmulas, e nenhuma frase se formava, como se fosse a lei desta linguagem. Esta fala ao mesmo tempo muito cultural e muito selvagem era sobretudo lexical, esporádica; cons- 
tituía em mim, através de seu fluxo aparente, um descontínuo definitivo: esta não-frase não era de modo algum algo que não tivesse tido poder para chegar à frase, que tivesse existido antes da frase; era: aquilo que existe eternamente, soberbamente, fora da frase. (1987:65)

Fora da frase e fora do tempo, a jubilação encantatória da música do piano e da chuva que cai tematizam os sentidos enquanto elementos estruturadores e presentificadores da memória: ouvir, ver, cheirar. Através dos sentidos, mas fora da frase, esta reconfiguração da memória pertence à significância, aos incidentes pulsionais, a uma outra linguagem atapetada de pele, a toda uma estereofonia do corpo, que se implica no acto de uma memória sensível.

É por esta ponte sensível e inarticulável, fora do tempo, que se faz a ligação entre a actividade da memória individual e a social, uma vez que esse tempo disjuntivo da temporalidade é o locus da identificação simbólica, que estrutura o domínio intersubjectivo - o domínio da outridade e do social - onde "nos identificamos com o outro exactamente no ponto em que ele é inimitável, no ponto em que se esquiva da semelhança" (Bhabha, 1998:257). Ainda seguindo a reflexão do ensaísta indiano, tal momento liminar - que se esquiva da semelhança - produz uma estratégia subversiva de agência subalterna "que negocia a sua própria autoridade através de um processo de descosedura iterativa e religação insurgente, incomensurável; não requer uma temporalidade de continuidade ou acumulação" (ibid.).

Se, por um lado, a memória, nas narrativas em análise, se constitui elaborada a partir de fragmentos pessoais, que são reorganizados numa dimensão que lhe dá uma heterogeneidade, uma vez que imita a inconsequência do fluir da consciência e dos sentidos, por outro, pode-se caracterizá-la como um território no qual a relação pessoal está relacionada com uma experiência social de diversidade.

É por essa rede filigranada que, muitas vezes, se chega a uma suposta experiência de identidade pela diferença. Deste modo, o tempo colonial, ou outras temporalidades culturais e religiosas diversas, em estado fragmentário, fora da frase do presente, se deixam percepcionar como temporalidades negociadas, que se esquivam da semelhança e se apresentam como exterioridade convocada e como espectáculo interior. É o caso, por exemplo, do bordado de Jamal no conto "O pano encantado" de JPBC, em que se caracteriza uma outridade 
histórico-religiosa, em que a temporalidade islâmica se revela tecida, e que percorre genotextualmente uma parte do mapa humano da Ilha de Moçambique.

No ano seguinte, 1897, o pano mostra Ma'ruf desembarcando na Ilha de Moçambique - pequenino feijão bordado que só com muita atenção conseguimos descobrir - para ali estabelecer a sua confraria Shadhuliyya Yashrutiyya, e assim espalhar a Divina Palavra. Com alguma imaginação podemos mesmo ver que estava um dia de sol, e maré cheia, quando ele desembarcou onde mais tarde se construiria a Mesquita Grande, uma meia-lua assinalando os dois factos, um ponto de armas retorcido assinalando as águas. A partir daqui, a maneira como a história é bordada no pano corresponde à felicidade no coração de Jamal, aos gestos suaves que tinha quando bordava, que causaram espanto e admiração na família quando o viu assim. Bordou-a numa noite fresca e clara, a lua cheia quase tornando irrelevante a luz do candeeiro. (S:39)

\section{Relato, conto, romance $\&$ narrativa - voz \& escrita}

Na escrita de Manuel Rui há uma incorporação de vozes, diversos falares, gírias e sons, à maneira de um mercado, tal como Roland Barthes alude na citação referida mais acima. Os diversos estratos sociais atravessam a textualidade e a noção de polifonia é útil, porque permite caracterizar as operações carnavalescas (na acepção rabelaisiana) que se realizam nesta narrativa.

O diálogo entre o erudito e o popular, a intersecção entre a voz autoral e as diversas vozes que dimensionam a integração do "povo" no texto, sua inscrição como objecto pedagógico e sujeito performativo. Semelhante estratégia constitui mais do que um acto de integração da escrita no cânone da cultura oral tradicional, mais do que uma homenagem às culturas locais. A representação da oralidade e das vozes populares permite a modernidade textual, enquanto cruzamento de dicções, formas e géneros e uma espécie de reivindicação de uma memória "literária" transtemporal.

Por outro lado a perturbante presença da mimetização de uma "escrita em voz alta" (Barthes, 1986:85), recupera aquilo que a retórica designa por actio, conjunto de regras que permitem a exteriorização corporal do discurso, o empenho teatral da voz. Não é por acaso que ao longo de $O$ manequim e o piano, 
"as notas, falas, relatos, bocas" se conjugam com a ideia de também fazer/encenar uma peça de teatro. Com efeito, o diálogo encenado na escrita de Manuel Rui é uma estratégia de representação dramatizada em que o narrador, dissimulando a sua presença, dá palavra às personagens “ce qui compte, c'est non plus l'existence de certains idiolectes sociaux, etc. , décelables à l'aide de critères purement linguistiques, mais l'angle dialogique sous lequel ils s'opposent ou se justaposent à l'interieur de l'oeuvre'. (BAKHTINE, 1970:239).

Esta heterogeneidade de uma escrita, que simula a narração ou interlocução oral, permite lembrar as palavras de Walter Benjamin no seu estudo sobre o Narrador, quando nos remete para as diferenças entre narrativa e romance:

A alma, o olho e a mão estão assim inscritos no mesmo campo. Interagindo, eles definem uma prática. Essa prática deixou de nos ser familiar. O papel da mão no trabalho produtivo tornou-se mais modesto, e o lugar que ela ocupava durante a narração está agora vazio. (Pois a narração, em seu aspecto sensível, não é de modo algum o produto exclusivo da voz. Na verdadeira narração, a mão intervém decisivamente com seus gestos, aprendidos na experiência do trabalho, que sustentam de cem maneiras o fluxo do que é dito). (1985:221)

$\mathrm{O}$ que me parece muito produtivo tanto na escrita de Manuel Rui quanto na de João Paulo Borges Coelho, que designa por conto - uma escrita que se alonga, grande parte das vezes, quase em novela, ou narrativa de memórias - à falta de melhor designação, é a mutação das noções canónicas de género literário. Talvez a palavra "narrativa", enquanto género misto, que articula convenções dos géneros orais e outras que se prendem às mais recentes formas como o romance, se adeque mais tanto num caso como no outro.

Recorrendo de novo a Walter Benjamin, o autor, ao considerar o que separa o romance da narrativa (e da epopeia no sentido estrito), considera entre outros aspectos a vinculação daquele ao livro, à imprensa.

$\mathrm{O}$ que distingue o romance de todas as outras formas de prosa - contos de fada, lendas e mesmo novelas, é que ele nem procede da tradição oral nem a alimenta. Ele se distingue, especialmente da narrativa. $\mathrm{O}$ narrador retira da experiência o que ele conta: sua própria experiência ou a relatada pelos outros. E incorpora as coisas narradas à experiência dos seus ouvintes. O romancista segrega-se. A origem do romance é o indivíduo isolado que não 
pode mais falar exemplarmente sobre suas preocupações mais importantes, que não recebe conselhos nem sabe dá-los. (1985:201)

Benjamin explica ainda que a narrativa "é consagrada a um herói, uma peregrinação, um combate: a segunda a muitos factos difusos. Em outras palavras, a rememoração, musa do romance, surge ao lado da memória, musa da narrativa" (1985:211); "Num caso "o sentido da vida" e no outro "a moral da história" - essas duas palavras de ordem distinguem entre si o romance e a narrativa, permitindo-nos compreender o estatuto histórico completamente diferente de uma e de outra forma" (1985:212).

O que eu gostaria de deixar em discussão neste ensaio, e para desenvolvimento em outras páginas, é a problematização, no âmbito dos estudos genológicos, da questão do romance, e outras formas narrativas africanas, que me parecem partilhar características tanto da narrativa (de matriz oral), como do romance, novela ou de memórias.

Enquanto actos de escrita estas narrativas recorrem à teatralização do seu próprio acto narrativo, convocando a Voz, e dando lugar a vários códigos estruturadores da actio retórica. Por outro lado conjugam "o sentido da vida" à "moral da história", ou seja, a intencionalidade é simultaneamente pedagógica, moral e crítica, exaltante e céptica, combinando características dos modos épico e romanesco.

Parece-me que é esta ambiguidade formal que torna estes textos diferenciais e, de certa maneira, inclassificáveis, enquadrados nas designações usadas pela poética ocidental.

Em termos metafóricos, e considerando o sentido de transporte que a palavra veicula, os géneros foram apropriados e reelaborados por estas narrativas, do mesmo modo que o tempo colonial - fora da frase - que se revela nas imagens da casa, do pano encantado, das lápides de Manau, do manequim, das casas de ferro, do som do piano. Fragmentos da memória e recomposição genológica, reconfigurados e fantasmáticos, introduzem no presente da escrita, uma enunciação diferencial e não monológica.

Retomando a reflexão de Bhabha, em "DissemiNação: o tempo, a narrativa e as margens da nação moderna", que fragmentariamente acompanhou a tessitura deste artigo, retomamos uma das suas questões:

"Agora não há razão para crer que tais marcas de diferença não possam inscrever uma 'história' do povo ou tornar-se os lugares de reunião da soli- 
dariedade política. Contudo, não celebrarão a monumentalidade da memória historicista, a totalidade da sociedade ou a homogeneidade da experiência cultural. (...) De que modo se pode encontrar o passado como uma anterioridade que continuamente introduz uma outridade dentro do presente?" (1998:222)

\section{Referências Bibliográficas}

COELHO, João Paulo Borges. Indícos Indícios I Setentrião. Lisboa: Caminho, 2005. RUI, Manuel. O Manequim e o Piano. Lisboa: Cotovia, 2005.

BAKHTINE, M. , Esthétique et théorie du roman. trad. D. Olivier. Galimard: Paris, 1978. BARTHES, Roland. O Praz̧er do Texto. São Paulo: Editora Perspectiva, 1987. BHABHA, Homi K. O Local da Cultura. Belo Horizonte: Editora UFMG, 1998. BENJAMIN, Walter. Magia e Técnica, Arte e Política. São Paulo: Editora Brasiliense, 1985.

CHAVES, Rita, "Notas sobre a Ficção e a História em João Paulo Borges Coelho". In MENESES, M. ;

RIBEIRO, M. (org). Moçambique: das palauras escritas. Porto: Afrontamento, 2008. NORA, Pierre (ed). Les lieux de la Mémoire. La République. Paris: Gallimard, 1984.

VIDAL-NAQUET, Pierre. Les juifs, la Mémoire et le présent. Paris: La Découverte,1991.

Recebido em 09 de abril e aprovado em 02 de maio de 2010. 